\title{
Quantitative Determination of Acetic Acid in Gefitinib by Reverse Phase HPLC
}

\author{
AJAY SINGH RAWAT ${ }^{*}$, KAMLESH CHAUHAN, YOGENDRASINH PARMAR, \\ POOJA SANNIGRAHI, DIVYESH PATEL, CHANDRAKANT BELWAL and \\ ANAND VARDHAN
}

Sterling Biotech Limited, Jambusar State Highway, Village Masar 391421, Taluka, Padra, Distt: Vadodaram Gujarat, India

ajaysingh_rawat@sterbio.com

Received 13 July 2013 / Accepted 30 August 2013

\begin{abstract}
A improved, simple and economic reverse phase high performance liquid chromatography (RP-HPLC) method has been developed and validated as per ICH guidelines for the quantification of acetic acid present in Gefitinib as an solvent impurity. Validation studies demonstrated that the proposed RP-HPLC method is simple, specific, rapid, reliable and reproducible. The high recovery and low relative standard deviation confirm the suitability of the proposed method for the routine quality control analysis for the quantification of acetic acid in Gefitinib.
\end{abstract}

Keywords: Gefitinib; Acetic acid; High Performance Liquid Chromatography; Method Validation

\section{Introduction}

Gefitinib $^{1}$ chemically known as $N$-(3-chloro-4-fluorophenyl)-7-methoxy-6-[3-(4-morpholinyl) propoxy]-4-quinazolinamide and represented as in Figure 1, is a drug used for certain breast, lung and other cancers. Gefitinib is an EGFR inhibitor ${ }^{2-5}$, like erlotinib, which interrupts signaling through the epidermal growth factor receptor (EGFR) in target cells. Therefore, it is only effective in cancers with mutated and overactive EGFR.

Gefitinib is the first selective inhibitor of epidermal growth factor receptor's (EGFR) tyrosine kinase domain. Thus gefitinib is an EGFR inhibitor. The target protein (EGFR) is a family of receptors which includes Her1 (erb-B1), Her2 (erb-B2), and Her 3(erb-B3). EGFR is over expressed in the cells of certain types of human carcinomas - for example in lung and breast cancers. This leads to inappropriate activation of the anti-apoptotic Ras signalling cascade, eventually leading to uncontrolled cell proliferation. Research on gefitinib-sensitive non-small cell lung cancers has shown that a mutation in the EGFR tyrosine kinase domain is responsible for activating anti-apoptotic pathways. These mutations tend to confer increased sensitivity to tyrosine kinase inhibitors such as gefitinib and erlotinib. Of the types of non-small cell lung cancer histologies, adenocarcinoma is the type that most often harbors these mutations. These mutations are more commonly seen in Asians, women and non- smokers 
(who also tend to more often have adenocarcinoma). Gefitinib inhibits EGFR tyrosine kinase by binding to the adenosine triphosphate (ATP)-binding site of the enzyme. Thus the function of the EGFR tyrosine kinase in activating the anti-apoptotic Ras signal transduction cascade is inhibited, and malignant cells are inhibited.

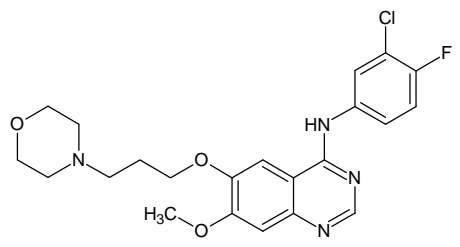

\section{Experimental}

Figure 1. Chemical structure of Gefitinib

HPLC grade acetic acid (Assay 99.80\%) was obtained from S D Fine Ltd and a pure inhouse sample of Gefitinib with assigned purity $99.90 \%$ was obtained for method development and validation. Acetonitrile HPLC grade (99.95\% Assay), potassium dihydrogen phosphate A.R. Grade (99.50 \% Assay) and ortho phosphoric acid A.R. Grade (85\% Assay) were procured from Merck. While highly pure Milli Q Water obtained from Millipore Milli-Q plus purification system was used wherever aqueous preparations were involved. Electronic analytical micro balances XP-26 of Mettler, Micro pipette (Biosystem, 10-100 $\mu \mathrm{l}$, and 100-1000 $\mu \mathrm{l}$ ) were used.

\section{Instrumentation and chromatographic conditions}

The chromatographic separation was performed on Waters Alliance 2695 separation module with 2487 dual $\lambda$ absorbance detector. The data were processed using Empower 2.0 software. The analytical conditions used were, Inertsil ODS-2, 250X4.6 mm, $5 \mu \mathrm{m}$ column, with a flow rate $1.0 \mathrm{~mL} / \mathrm{min}$, a gradient method as depicted in Table 1 with water containing $1.36 \mathrm{~g} / \mathrm{L}$ potassium dihydrogen phosphate $\mathrm{pH}$ adjusted to 3.5 by dilute orthophosphoric acid (Buffer) in pump A and acetonitrile in pump B was performed. The run time was set at 35 min and column temperature was maintained at ambient. The volume of injection was $20 \mu \mathrm{L}$. Prior to injection of analyte, the column was equilibrated for 30-40 min with mobile phase. The eluents were monitored at $210 \mathrm{~nm}$. The HPLC chromatograms were integrated for the main peaks and acetic acid while peaks due to blank were not integrated.

Table 1. Gradient program

\begin{tabular}{cccc}
\hline Time (minutes) & PUMP- A & PUMP-B & Flow \\
\hline 0.00 & 100 & 25 & 1.0 \\
8.00 & 100 & 25 & 1.0 \\
10.00 & 50 & 30 & 1.0 \\
20.00 & 50 & 30 & 1.0 \\
23.00 & 100 & 50 & 1.0 \\
35.00 & 100 & 50 & 1.0 \\
\hline
\end{tabular}

\section{Preparation of mobile phase and diluent}

The buffer was prepared by taking $1.36 \mathrm{~g}$ of potassium dihydrogen phosphate in $1000 \mathrm{~mL}$ of water which was sonicated, filtered through 0.45 micron filter and adjusted to $\mathrm{pH} 3.5$ with dilute orthophosphoric acid (Pump A). Acetonitrile of HPLC grade was degassed and used as mobile phase in pump B. Solution of $17.4 \mathrm{~mL}$ of concentrate $\mathrm{HCl}$ in $1000 \mathrm{~mL}$ with Milli$\mathrm{Q}$ water was used as diluent. 


\section{Preparation of sample and standard solutions}

$100 \mathrm{mg}$ of acetic acid was taken in a $100 \mathrm{~mL}$ volumetric flask, dissolved in dil. $\mathrm{HCl}$ solution (i.e. $17.4 \mathrm{~mL}$ of conc. $\mathrm{HCl}$ in $1000 \mathrm{~mL}$ Milli-Q water) and made up to $100 \mathrm{~mL} .5 \mathrm{~mL}$ of this solution was further diluted to $100 \mathrm{~mL}$ using the same dil. $\mathrm{HCl}$ solution. $250 \mathrm{mg}$ of Gefitinib was taken into $25 \mathrm{~mL}$ volumetric flask and made up to $25 \mathrm{~mL}$ using the same dil. $\mathrm{HCl}$ solution.

\section{Construction of linearity}

The concentrations of analyte were prepared by suitable dilution of stock solution to get concentrations in the linear range of $0.0015 \mathrm{mg} / \mathrm{mL}$ to $0.07 \mathrm{mg} / \mathrm{mL}$. Each of these solutions $(20 \mu \mathrm{L})$ was injected three times into the column, the peak area and retention times were recorded. The calibration curve was constructed by plotting the ratio of the peak area of acetic acid $(Y)$ against concentration $(X)$ which revealed a good correlation between concentration and peak area as represented in Figure 2.

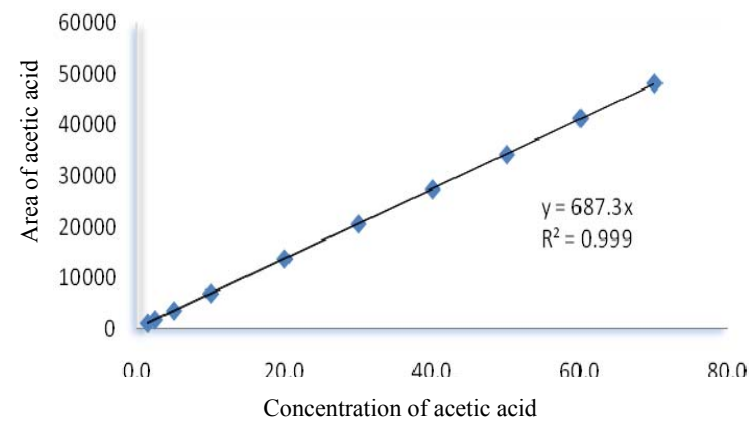

Figure 2. Linearity curve

\section{Results and Discussion}

As the routine in-house purification procedure of Gefitinib involved acetic acid as one of the components in the final step it was essential to develop and demonstrate that the manufactured Gefitinib final API was substantially free of acetic acid or more desirably below the ICH limit requirements of $5000 \mathrm{ppm}$. The main objective thus to develop a quantitative method $^{6-11}$ to determine the acetic acid content present in the Gefitinib. In analytical research the time and cost for the method development, validation and the method of quantification is greatly considered hence a HPLC method development was preferred over GC. Thus initially an HPLC method was optimized to provide a good separation of acetic acid and Gefitinib (acceptable theoretical plates and resolution between peaks) with a sufficient sensitivity and suitable peak symmetry (peak tailing factor $<2$ ). For this purpose, the analytical column, solvent selection, mobile phase composition, flow rate and detector wavelength were studied. The use of hydrophobic stationary phases usually provides adequate retention of organic non polar molecules. The chromatographic separation was achieved using an RP C18 column because it was suitable to resolve the acetic acid with adequate resolution and gave symmetrical peak shapes.

Thus a reverse phase high performance liquid chromatographic (RP-HPLC) method was developed and later validated for the quantification of acetic acid in Gefitinib (as discussed in material and method section). In this method the retention times observed for Gefitinib and acetic acid were 13.5 and $7.0 \mathrm{~min}$, respectively. A typical chromatograms of acetic acid spiked in Gefitinib is shown in Figure 3. 


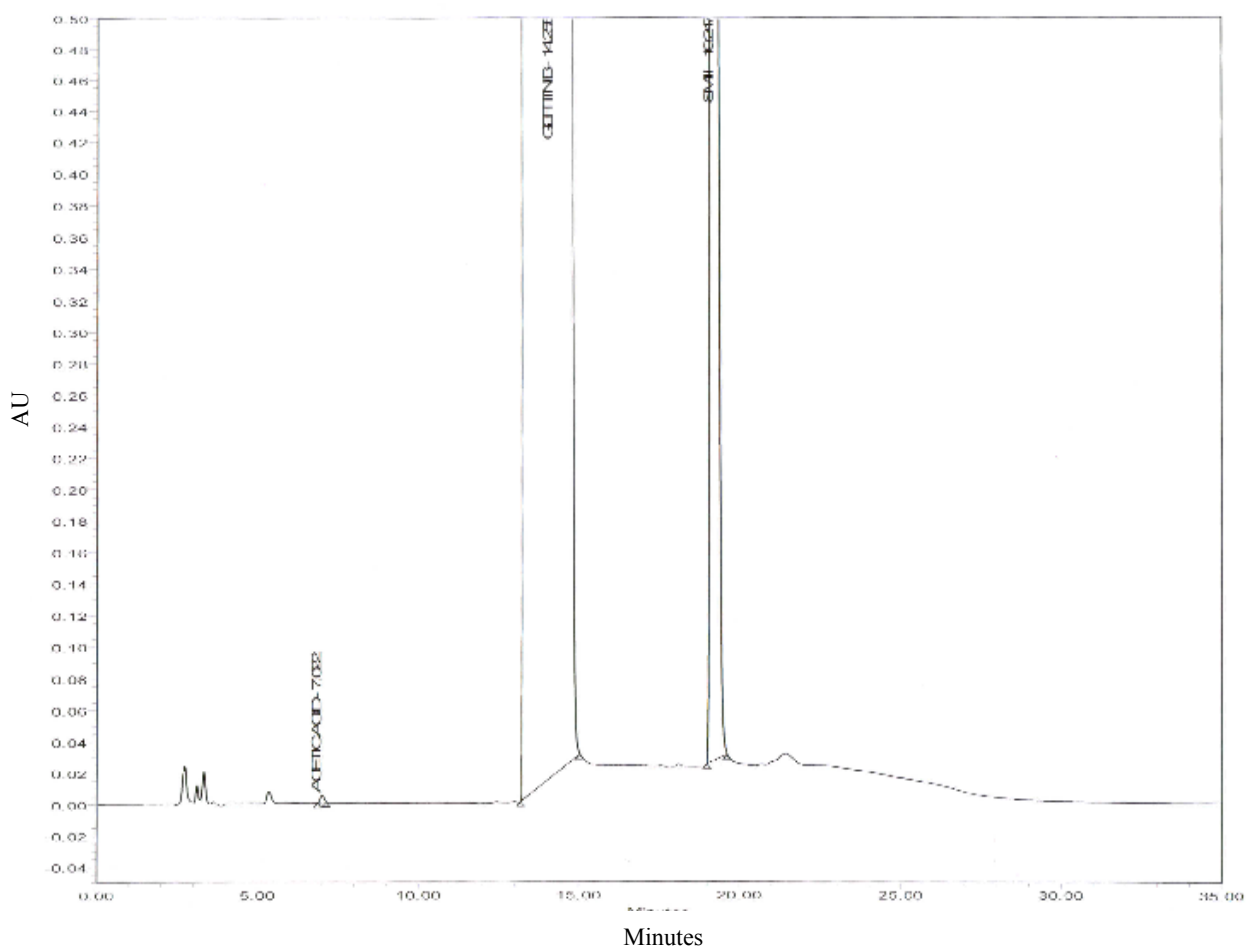

Figure 3. HPLC chromatograph of acetic acid spiked in Gefitinib

A standard plot was constructed by plotting the ratio of the peak area of acetic acid $(Y)$ against concentration $(X)$. It was found to be linear with a correlation coefficient $\left(r^{2}\right)$ of 0.999 , the corresponding linear regression equation being $y=687.3 \mathrm{x}+00$. The results are shown in Table $2 \& 3$.

Table 2. Linearity of the method

\begin{tabular}{cc}
\hline Concentration, $\mathrm{mg} / \mathrm{mL}$ & Average peak area \\
\hline 0.0015 & 1205 \\
0.0025 & 1868 \\
0.005 & 3628 \\
0.01 & 7019 \\
0.02 & 13831 \\
0.03 & 20628 \\
0.04 & 27426 \\
0.05 & 34246 \\
0.06 & 41288 \\
0.07 & 48122 \\
\hline
\end{tabular}

Table 3. Results of Linearity

\begin{tabular}{cc}
\hline Parameters & Values \\
\hline Linearity & $0.0015-0.07$ \\
Regression equation & $687.3 \mathrm{x}+00$ \\
Correlation coefficient $\left(\mathrm{r}^{2}\right)$ & 0.999 \\
\hline
\end{tabular}


The precision of the method was determined by repeatability and intermediate precision studies. Repeatability was evaluated by performing six determinations $(n=6)$ at the same concentration, during the same day, under the same experimental conditions. Intermediate precision was evaluated by comparing the results on different days with different analysts. The result revealed the precision with \% RSD for intraday and interday 0.66 and 0.82 , respectively. The results are shown in Table 4.

Table 4. Intraday and interday precision of the method

\begin{tabular}{ccc}
\hline \multirow{2}{*}{ Test } & \multicolumn{2}{c}{ Area of acetic acid } \\
\cline { 2 - 3 } & Day-I & Day-II \\
\hline 1 & 15456.50 & 16174.50 \\
2 & 15489.00 & 16031.00 \\
3 & 15404.50 & 15946.50 \\
4 & 15308.50 & 15796.50 \\
5 & 15213.50 & 15903.50 \\
6 & 15410.00 & 15901.00 \\
Average & 15380.33 & 15958.83 \\
STDEV & 102.05 & 130.10 \\
\% RSD & 0.66 & 0.82 \\
\hline
\end{tabular}

To ensure the reliability and accuracy of the method, the recovery studies were carried out by adding a known quantity of acetic acid with Gefitinib and contents were reanalyzed by the proposed method. Accuracy was evaluated at three different concentrations equivalent to 80,100 and $120 \%$, by adding known amount of acetic acid to the sample of known concentration and calculating the recovery of acetic acid with \% RSD and $\%$ recovery for each concentration. The mean \% recoveries were 97.24 to 97.49 and the values are shown in Table 5. The high recovery of acetic acid indicated that the proposed method for quantification of acetic acid in Gefitinib was highly accurate.

Table 5. \% Recovery of the method

\begin{tabular}{cccc}
\hline Test & $80 \%$ Level & $100 \%$ Level & $120 \%$ Level \\
\hline 1 & 97.69 & 97.99 & 97.44 \\
2 & 96.90 & 97.92 & 97.55 \\
3 & 97.14 & 98.16 & 97.49 \\
Average & 97.24 & 98.02 & 97.49 \\
STDEV & 0.41 & 0.12 & 0.06 \\
\% RSD & 0.42 & 0.13 & 0.06 \\
\hline
\end{tabular}

Suitability test was employed to establish the parameters such as tailing factor, theoretical plates, resolution, limit of detection and limit of quantification. The System suitability parameters were established and found to be within acceptable limits and the proposed method indicating that the test method was robust for all variable conditions. The results are shown in Table 6.

The robustness of the method was investigated by making small deliberate changes in the chromatographic conditions at three different levels. The chromatographic conditions selected were flow rate $(1,1.1$ and $0.9 \mathrm{~mL} / \mathrm{min}), \mathrm{pH}$ of buffer in the mobile phase $(3.5,3.2$ and $3.8 \mathrm{pH}$ ) and the column (Inertsil ODS-3V C18, $4.6 \mathrm{~mm} \mathrm{X} 250 \mathrm{~mm}, 5 \mu \mathrm{m}$ and Inertsil ODS-2 C18, $4.6 \mathrm{~mm} \times 250 \mathrm{~mm}, 5 \mu \mathrm{m})$. The results are shown in Table 7. 
Table 6. System suitability parameters

\begin{tabular}{ll}
\hline Parameter & Value \\
\hline Retention time (min) & 6.98 \\
Theoretical plates & 15005 \\
Tailing factor & 1.0 \\
Resolution & 5.01 \\
Linearity range $(\mathrm{mg} / \mathrm{mL})$ & $0.0015-0.07$ \\
Limit of detection $(\mathrm{mg} / \mathrm{mL})$ & 0.0035 \\
Limit of quantification $(\mathrm{mg} / \mathrm{mL})$ & 0.016 \\
\hline
\end{tabular}

Table 7. Robustness of the method

\begin{tabular}{cccccc}
\hline & \multicolumn{2}{c}{ Change in Flow } & \multicolumn{2}{c}{ Change in Buffer $\mathrm{pH}$} & Column change \\
\cline { 2 - 6 } & $1.1 \mathrm{~mL} / \mathrm{min}$ & $0.9 \mathrm{~mL} / \mathrm{min}$ & $3.2 \mathrm{pH}$ & $3.8 \mathrm{pH}$ & Inertsil ODS-2 \\
\hline Area of Acetic acid & 12073 & 14716 & 13186 & 14057 & 12666 \\
\% RSD of Area & 0.80 & 0.51 & 0.39 & 0.19 & 0.24 \\
\% Acetic acid & 0.21 & 0.22 & 0.22 & 0.23 & 0.20 \\
\hline
\end{tabular}

The limits of detection (LOD) and quantitation (LOQ) were calculated by the method based on the standard deviation (SD) and the slope $(S)$ of the calibration plot, using the formulae $\mathrm{LOD}=3.3 / \mathrm{S}$ and $\mathrm{LOQ}=10 / \mathrm{S}$. Specificity of the proposed method demonstrated acetic acid does not interfere in the Gefitinib peak. Furthermore, well shaped peaks indicate the specificity of the method.

\section{Conclusion}

A gradient RP-HPLC method for quantification of acetic acid present in Gefitinib was developed also the validation data demonstrates a high precision and accuracy, which proves the reliability of the developed method. In addition to the above the short runtime and cheaper mobile phase involved in the method are advantageous for analyzing routine quality control samples for the quantification of acetic acid in Gefitinib bulk drug.

\section{Acknowledgement}

We thank our Organic synthesis department for providing material support in timely manner.

\section{References}

1. Hopkinson K and Macclesfield G, Quinazoline Derivatives, US patent 5770599.

2. Anderson N G, Ahmad T, Chan K, Dobson R and Bundred N J, Int J Cancer, 2001, 94, 774.

3. Kris M G, Natale R B, Herbst R S, Lynch T J Jr, Prager D, Belani C P, Schiller J H, Kelly K, Spiridonidis H, Sandler A, Albain K S, Cella D, Wolf M K, Averbuch S D, Ochs J J and Kay A C, J Am Med Assoc., 2003, 290(16), 2149-2158

4. Arteaga C L and Johnson D H, Curr Opin Oncol., 2001, 13, 491-498.

5. Raben D, Helfrich B A, Chan D, Johnson G and Bunn PA Jr., Semin Oncol., 2002, Suppl 4, 37-46.

6. Peer Basha D, Ravi Shankar K and Kiranmayi G V N, Int J Chem Sci., 2012, 10(1), 437-448.

7. Ewaschuk Julia B, Naylor Jonathan M, Barabash Wade A and Zello Gordon A, $J$ Chromatogr, B: Anal Technol Biomed Life Sci., 2004, 805(2), 347-351.

8. Reddy P P, Balram V M and Mohan G K, Int J Chem Res., 2012, 2(6), 1-8.

9. Kumar V K, Raju N A, Begum S, Rao J S and Satyanarayana T, Res J Pharm Tech., 2009, 2(2), 341.

10. Venkataraanna M, Somaraju I V and Babu K S, Am J Anal Chem., 2011, 2(1), 75-83.

11. Ratnakumari A, Rajeswari A and Sobha K, Int J Adv Pharm Sci., 2010, 1(1), 118-122. 